\title{
Intrauterine Device Dosage Form
}

National Cancer Institute

\section{Source}

National Cancer Institute. Intrauterine Device Dosage Form. NCI Thesaurus. Code C47915.

A solid intended for placement within the uterine cavity where active and/or inert ingredient(s) are released from an apparatus at a controlled rate. 